\title{
Regarding the paper: Hydroview lens implant calcification-186 exchanges at a district general hospital, by P Syam et al
}

Eye (2008) 22, 323-324; doi:10.1038/sj.eye.6702799

With the introduction of foldable materials, a variety of soft hydrophilic acrylic intraocular lenses (IOLs) have been introduced into the market. Although many of those are performing well, with the increasing 'pore' sizes of the ultrastructure, chemical-binding sites, ageing changes, as well as constant diffusion of water plus ions, there is a potential for late changes in the molecular or physical structure of these lenses, as well as interaction with ions, proteins and fatty acids. These may lead to clinically observable opacities and material changes later in the postoperative course. Optic calcification of some hydrophilic acrylic IOL designs has been a significant complication leading to IOL explantation since 1999. Four major IOL designs manufactured in the US were involved in the problem: the Hydroview (Bausch and Lomb), ${ }^{1,2}$ the MemoryLens (Ciba Vision), ${ }^{3,4}$ the SC60B-OUV (Medical Developmental Research), ${ }^{5-7}$ and the Aqua-Sense (Ophthalmic Innovations International). ${ }^{8,9}$ The deposits causing the opacification were basically found on the optical surfaces of the Hydroview and the MemoryLens, while they were predominantly found within the substance of the SC60B-OUV and the Aqua-Sense. Surface deposits were also significantly observed with this latter design. Histochemical methods, as well as analyses of surface confirmed the composition of the deposits to be at least in part of calcium and phosphate.

In this issue, Syam et $a l^{10}$ described the experience at a district hospital with 174 consecutive lens exchanges because of calcification of the Hydroview lens.

M Tetz and L Werner

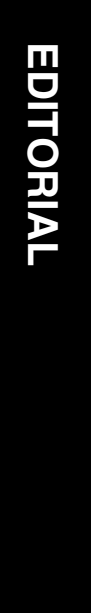

Interestingly, in their series, the first calcified IOLs requiring exchange began to appear in late 2002 , with the onset of symptoms due to the calcification being as late as 260 weeks after implantation (65 months). In our experience with pathological analyses of more than 100 Hydroview lenses explanted because of calcification, performed at the John A. Moran Eye Center, University of Utah, and the Berlin Eye Research Institute, the interval between the cataract procedure and the time the opacification of the lenses was noted ranged from 5 to 48 months (19.75 \pm 11.88 months). The authors appropriately described the fact that often the patients presented with a presumed diagnosis of posterior capsule opacification. Unnecessary posterior capsulotomies may jeopardize the implantation of a new IOL in the capsular bag, after explantation of the calcified lens. They also render the explantation procedure more challenging. Out of the eyes with intact posterior capsules in the study by Syam et al,,$^{10} 5.6 \%$ needed anterior vitrectomy, against $32 \%$ of the eyes with previous capsulotomies. We have also demonstrated in previous studies that Nd:YAG laser applications cannot clean the optic surfaces of the IOL of the calcified deposits. ${ }^{1,2}$

In 1997, Bausch and Lomb changed the Hydroview lens packaging system to incorporate the SureFold holder/folder. As the silicone gasket sealing the new SureFold cap was the only difference in the manufacturing and packaging of the lenses exhibiting calcification, this gasket came under suspicion early. Guan $e t ~ a l^{11}$ have recently published their results using the model constructed for analysis of the calcification process with the Hydroview
Berlin Eye Research Institute, Alt-Moabit, Berlin, Germany

Correspondence: M Tetz, Berlin Eye Research Institute, Alt-Moabit 98/99, Berlin D-10559, Germany Tel: + 49030398098 50; Fax: + 4903039809844 . E-mail: gm@ atk-spreebogen.de 
lens. The authors evaluated the role of long chain saturated fatty acids present in the aqueous humour on the process. The Hydroview lenses were exposed to cyclic silicone compounds, and treated with different fatty acids, at different concentrations. Then, they were rinsed and placed in supersaturated solutions of calcium chloride and potassium dihydrogen phosphate. They demonstrated that the fatty acids cannot bind directly to the IOL surfaces and therefore cannot also induce calcification by themselves. However, hydrophobic cyclic silicone compounds adsorbed at the IOL surfaces interacted strongly with the hydrophobic carbon chains of the fatty acids, to create a layer of fatty acids oriented with polar, functional hydrophilic groups exposed to the aqueous solution, providing nucleation sites for calcium/phosphate. Fatty acids with shorter chains were more readily adsorbed at the IOL-cyclic silicone surfaces, resulting in shorter nucleation induction times.

Nucleation was also promoted by increasing the concentration of the fatty acids used. Furthermore, the same authors evaluated the effects of precoating of the Hydroview with different ophthalmic viscosurgical devices, and determined that they displayed different calcification properties.

Dorey et $a l^{12}$ had already analysed 17 explanted Hydroview lenses and demonstrated the presence of the element silicon mainly at the centre of the calcified deposits, in surface analyses for elemental composition. Similar to the study by Dorey et $a l^{12}$ on explanted Hydroview lenses, for the first time the presence of the element silicon in relation to calcified deposits with the three other major hydrophilic acrylic designs that have been associated with calcification was demonstrated by one of us. ${ }^{9}$ Further studies are therefore necessary to investigate the possible sources of this type of contamination onto IOLs. The manufacturer of the Hydroview lens has since changed its packaging, which is now sealed with a gasket made from a perfluoroelastomer (Green G et al. An issue resolved. The Hydroview intraocular lens: development, early reports of calcification and subsequent actions. White paper Bausch and Lomb; 29 July, 2003). To the best of our knowledge, the lenses with the new packaging have not been associated with calcification. However, a long-term follow-up of patients implanted with these lenses is necessary to completely rule out the problem, as many questions remain unanswered and the precise combination of factors leading to IOL calcification is still unknown. Also, surgeons should have a strong suspicion of calcification when opacification is observed in eyes implanted with Hydroview lenses associated with the SureFold system. Prompt recognition of this condition will prevent unnecessary procedures, and potentially related complications.
With constant improvement in IOL technology and material development, it is our responsibility as clinical and pathological researchers to closely scrutinize all IOLs implanted for postoperative long-term complications, and encourage all efforts to eliminate any IOL material-derived and manufacturing-related problems. There are many others issues involved with the recall of patients, as described in the study by Syam et al. ${ }^{10}$ Despite the fact that there are questions about product liability and who covers the costs for additional surgical procedures (lens exchange etc), we feel it is important that in any individual case the patient's well-being should be the guideline for mutual actions taken by the doctor, manufacturer, and health authorities.

\section{References}

1 Werner L, Apple DJ, Escobar-Gomez M, Öhrström A, Crayford BB, Bianchi R et al. Postoperative deposition of calcium on the surfaces of a hydrogel intraocular lens. Ophthalmology 2000; 107: 2179-2185.

2 Pandey SK, Werner L, Apple DJ, Gravel JP. Calcium precipitation on the optical surfaces of a foldable intraocular lens: a clinicopathological correlation. Arch Ophthalmol 2001; 120: 391-393.

3 Neuhann IM, Werner L, Izak AM, Pandey SK, Kleinmann G, Mamalis $\mathrm{N}$ et al. Late postoperative opacification of a hydrophilic acrylic (hydrogel) intraocular lens: a clinicopathological analysis of 106 explants. Ophthalmology 2004; 111: 2094-2101.

4 Tehrani M, Mamalis N, Wallin T, Dick HB, Stoffelns BM, Olson $\mathrm{R}$ et al. Late postoperative opacification of memorylens hydrophilic acrylic intraocular lenses: case series and review. J Cataract Refract Surg 2004; 30: 115-122.

5 Werner L, Apple DJ, Kaskaloglu M, Pandey SK. Dense opacification of the optical component of a hydrophilic acrylic intraocular lens: a clinicopathological analysis of 9 explanted lenses. J Cataract Refract Surg 2001; 27: 1485-1492.

6 Macky TA, Werner L, Soliman MM, Pandey SK, Izak AM, Apple DJ. Opacification of two hydrophilic acrylic intraocular lenses 3 months after implantation. Ophthalmic Surg Lasers Imaging 2003; 34: 197-202.

7 Pandey SK, Werner L, Apple DJ, Kaskaloglu M. Hydrophilic acrylic intraocular lens optic and haptics opacification in a diabetic patient: bilateral case report and clinicopathological correlation. Ophthalmology 2002; 109: 2042-2051.

8 Izak AM, Werner L, Pandey SK, Apple DJ. Calcification of modern foldable hydrogel intraocular lens designs. Eye 2003; 17: 393-406.

9 Werner L, Hunter B, Stevens S, Chew JJL, Mamalis N. Role of silicon contamination on calcification of hydrophilic acrylic intraocular lenses. Am J Ophthalmol 2006; 141: 35-43.

10 Syam P, Byrne P, Lewis G, Husain T, Kleinmann G, Mamalis $\mathrm{N}$ et al. Hydroview lens implant calcification - 186 exchanges at a district general hospital. Eye 2007 (in press).

11 Guan X, Tang R, Nancollas GH. The potential calcification of octacalcium phosphate on intraocular lens surfaces. J Biomed Mater Res 2004; 71A: 488-496.

12 Dorey MW, Brownstein S, Hill VE, Mathew B, Botton G, Kertes PJ et al. Proposed pathogenesis for the delayed postoperative opacification of the hydroview hydrogel intraocular lens. Am J Ophthalmol 2003; 135: 591-598. 